\title{
Sociocultural Determinants of Fertility in the Mandingo (Mandinka) Tribe of the Gambia: Implications for Health Education
}

\author{
Omar Manjang, Jainaba Sey-Sawo, Haddy Tunkara-Bah, Ojo Idowu Opeyemi, Fidelis Okafor
}

\begin{abstract}
Background- The total fertility rate is 5.4 births per woman. This high fertility level has resulted in a very youthful population structure. Average life expectancy at birth is 63.4 years $(\mathrm{GBoS}, 2007)$.

Methodology- This study was conducted using a systematic review of literature on the Mandingo tribe of the Gambia, listening to music and songs on Mandingos, and through personal communication with some elderly men and women of the tribe.

Results- From the reviews and the personal interviews conducted, fertility enhancers among the Mandingos include; early marriage by Mandingo boys and girls, desire for couples to have male children, polygamy, extended family system, poor use of fertility control drugs/methods (family planning), children for economic and agricultural purposes. On the other hand, factors that hinder fertility among the Mandingos also include; separation during breast feeding (lactation amenorrhea), caste system among Mandingos, level of western education (highly educated have few children), employment status (employed women usually have few children), importance attached to virginity before marriage, differences in religion and avoidance of sex on religious bases (during fasting).

Conclusion- The findings of this study have shown that male dominance in decision making, family planning and sex, among the Mandingo tribe contributes significantly to the high fertility rate among this tribe. Love for male children,polygamy and desire for large families cannot be under estimated in promoting fertility among them. The status quo can be shifted by empowering their females through education and spending on them like they spend on their male kids.
\end{abstract}

Index Terms - fertility rate, family planning, Health Education .

\section{INTRODUCTION}

The Gambia is located midway on the bulge of the West Africa coast and stretches over 400 kilometers inland from west to east on either side of the River Gambia, varying in width from about $50 \mathrm{~km}$ near the mouth of the river to about $24 \mathrm{~km}$ upstream. The country is bound to the north, south,

Omar Manjang, Directorate of Nursing, Ministry of Health and Social Welfare, Quadrangle Banjul, The Gambia West Africa

Jainaba Sey-Sawo, School of Medicine and Allied Health Sciences, Department of Nursing University of the Gambia, Banjul, The Gambia West Africa.

Haddy Tunkara-Bah, , School of Medicine and Allied Health Sciences, Department of Nursing University of the Gambia, Banjul, The Gambia West Africa.

Ojo Idowu Opeyemi, The Gambia West Africa

Fidelis Okafor, The Gambia West Africa and east by the Republic of Senegal and to the west by the Atlantic Ocean. The River Gambia, which runs the entire length of the country from the Futa Jallon highlands in the Republic of Guinea to the Atlantic Ocean, divides the country's land area of 10,689 square kilometers almost equally into two halves: the South Bank and the North Bank (Gambia Bureau of Statistics [GBoS], 2007).

The main objectives of this study is to do a post mortem of the Mandingo tribe andfind out some of the social and cultural factors that enhance fertility among the Mandingo tribe of the Gambia. The study will also give us the opportunity to explore such social and cultural factors that hinder fertility among this tribe in the Gambia. It will also indicate to us why there are differences in fertility between the Mandingo and other tribes of the Gambia.

The Mandingo of Gambia is the largest ethnic group of people in the country. They are distributed across the length and breadth of the country. They are sometimes referred to as the Malinke or Mande and make up $42 \%$ of the population of Gambia. The Mandes are widespread even the Gambia, throughout the whole of West Africa particularly in Mali, Senegal and Guinea. The main ethnic groups in Gambia consist of Mandingo (42\%) of the overall population, Wolof $(16 \%)$, Fulani (18\%), Jola (10\%), Serahuli (9\%), other Africans (4\%), and non-Africans (1\%). Today, there are approximately between 11 to 20million Mandingos in West Africa (Mandinka Tribe, Gambia. Accessgambia.com).

These groups of people were looking for a better climate as well as farming and grazing land which they found near the big rivers Gambia, Senegal and Casamance. Another reason was their search for better trading possibilities near the Trans-Sahara-Route. Finally it was also princes` and generals` hope to reign over their own land, which was made possible, because the original inhabitants of the region lived on scattered farms and therefore weren't able to defend themselves effectively. Whereas at the beginning only single families dared to move, in the middle of the thirteenth century general TiramangTouray started a big campaign into the region which is today in the south of the eastern half of Gambia. He founded the KaabuEmpire and expanded into all directions, so that at the end of the thirteenth century the whole area with many different nationalities was under the Mandinkas rule (Mandinka Tribe, Gambia. Accessgambia.com).

Traditional Social Class Structure of theMandingo society was divided into four main groups. The Slaves, Caste group, 


\section{Sociocultural Determinants of Fertility in the Mandingo (Mandinka) Tribe of the Gambia: Implications for Health Education}

Commoners and Nobles in increasing hierarchy (bottom -top, slaves -nobles). Marriage among lower andupper groups/castes was strictly prohibited and was limited to within each group as a result; this can inhibit fertility because a potential bride and groom from different castes/social class will not be allowed to marry even if they love each other.

The system of governing under the Mandinka tradition is made up of three layers. The first is at the family level where the eldest male member of a household would automatically be the head and would have the last word on any disputes or decisions involving marriage, funeral rites and healthcare. As a result, fertility issues like the use of modern family planning commodities, the number of wives to be married by him/other male members of the family, having more children (in search of males) all of which affects fertility aremostly decided by the household head. At the second level, you have the head of the village (Alkalo) and at the third/state level, you have the king (Mansa).

Developmental Considerationsinclude the rite of passage which marks the beginning of adulthood for children. Between age four and fourteen, the youngsters have their genitalia ritually cut in separate groups according to their sex. The traditional teachings, in marriage, fertility, social responsibilities that they received during this passage prepare these young adults to form new families of their own.
Values Orientationis more recognized when children reached sexual maturity boys and girls ( 12 to 15 for girls $\& 18$ to 20 for boys). Now the boys have to work harder to enable them to pay their own bride price whiles the girls take part in cooking, preparing meals and laundering.

\section{Methodology}

This study was conducted using a systematic review of literature on the Mandingo tribe of the Gambia, listening to music and songs on Mandingoes, and through personal communication with some elderly men and women of the Mandingo tribe of the Gambia. These elderly men and women were said to be very wise and versed in the oral tradition and history of the Mandingo tribe. This is because they are Mandingos themselves, and therefore opportune to have gone through, witnessed, and also performed personally, some or all of these social and cultural determinants or factors that impact positively or negatively on the fertility trend of this very interesting tribe (Mandingo) of the Gambia. The researcher thus had first-hand information through personal communicationwith these wise and experienced men and women. All of these led to the facts presented in this paper, especially as reflected in table 1 below.

Table 1: Summary of Fertility Enhancers and Inhibitors in Mandingos

\section{Sociocultural Factors that Enhance Fertility in Sociocultural Factors that hinders Fertility in (Mandingos)}

\section{(Mandingos)}

\# Early marriages (12 to 15yrs) leads to having many children before reaching menopause

\# Emphasis at marriage, is on reproduction (having more and more children)

* Desire for a male child (to head the family and have more shares at inheritance)

* Desire for large families children to help support them at old age and on farms

* Strongly oppose abortion

* Opposes some forms of birth control

* High infant mortality rate lead to more births

* Children are needed to perform essential tasks (to economically support their siblings and parents)

* Living in rural areas (leads to poor access and affordability of family planning services)

* Preference for sons, raises a woman status in the family

\# Disgrace for a couple, particularly for the wife, not to have children in her marriage

\# Children are a symbol of well-being both socially and economically

* Early age at first intercourse can lead to teenage and unwanted pregnancies

* Household headship (the man decides when to have sex and what number of children to have)
* Avoidance of coitus on religious bases ( especially while fasting)

* Avoidance of coitus during breast feeding

Avoidance of coitus during menstruation

+ Emphasis on continence and celibacy

\# Girls in higher castes don't marry to those in lower castes

* Differences in religions also prevents marriage

* Exposure to mass media (sensitizes them)

* Giving the best part of the food to the household head (Makes women malnourish and anaemic)

* Living in urban areas (Increase access and affordability of family planning services)

* Exposure to household pollutants, pesticides, and industrial compounds (during farming or gardening and laundry/household chores)

* Early menopause (especially if this genetic condition runs in the family) can limit number of children

* Woman's fertility decreases as she gets older (she no longer ovulates and is unable to ovulate)

\# Obesity, ( women at around age 18yrs with extra kilos, leads to polycystic ovarian diseases)

* Women who are too thin and deficient in leptin, the hormone that controls hunger and feelings of satiety. (leads to absence of menstrual periods)
Subsistence agriculture system needing more 
hands on the farms

* Naming Ceremonies

\# Circumcision Ceremonies

\# Wedding Ceremonies

\section{IMPLICATIONS FOR HEALTH EDUCATION}

The determinants of fertility in this socio-culturally rich ethnic group of the Gambia (Mandingos),is hereby portrayed to show its implications for Health Education among all the age groups in this tribe. Such a post-mortem of the different strata of ages within Mandingos will be effectively done using theBloom's taxonomy which refers to a classification of different learning objectives. Bloom classifies educational objectives into three domains, namely:the affective domain, the psychomotor domain and the cognitive domain. Emphasis was placed on the cognitive domain leaving experts to identify the categories for the other domains.

\section{The cognitive domain}

The cognitive domain refers to categories related to knowledge, comprehension, and critical thinking of a particular topic. Bloom classified these categories into six levels, moving through the lowest order processes to the highest:

Knowledge involves recalling facts, terms, basic concepts and answers, while the verbs aspect include arranging, defining, duplicating, labeling, listing, memorizing, naming, ordering, recognizing, relating, recalling, repeating, reproducing and stating. Most Mandingos are knowledgeable in Islam, Arabic, Quran, Traditional and the customary laws. Most of these are handed down from one generation to another through folklore, traditional singers/Griots and also from parents to their kids. Some of these knowledge bases are prone to dilution through deletions and additions as time goes by but the key facts remain intact. Knowledge gained from the above relates to smiling, shaking hands, washing hands before eating, after visiting the toilet/bathroom, after touching pets/animal fur, before preparing food/feeding a child, after sneezing/blowing one's nose in the hands. This will significantly reduce the incidence of infectious diseases in all age groups and similarly the high cost of health care especially in the Gambia which is one of the middle and low income countries. Male circumcision which is compulsory inthis tribe is important in reducing penile cancer, some sexual transmitted diseases (STD), urinary tract infections (UTI) and encourages several important matrimonial messages, which are passed to the beneficiaries during this time. Type one and two female circumcision is also practiced to some extent by Mandingos but it has been implicated in a lot of health consequences for the female folk, including genital keloids, hemorrhage, vaginal scars and tightening, maternal and neonatal morbidity and mortality. Important messages relating to marriage, pregnancy and child bearing are also thought during this period. Breast-feeding for two years is also emphasized which serves as a form of family planning (lactation amenorrhea) thereby reducing the high fertility rate. Also infant, child and adult nutritious food preparation from locally grown food stuffs and their methods
Employment

of storage are passed on to the newly-wed couple by grand-mothers and fathers. Prompt burying of the dead in accordance with the Islamic faith (practiced by most Mandingos) is advised and practiced to avoid the spread of infection from corpses and reduce the cost of keeping them in mortuaries; this will impact positively on the poverty level of the members of the tribe.

Comprehensionby all age groups is facilitated through demonstrative understanding of facts and ideas by organizing, comparing, translating, interpreting, giving descriptions, and stating main ideas. The verbal aspects of such demonstration are to classify, describe, discuss, explain, express, identify, indicate, locate, recognize, report, restate, review, select and translate respectively. These are carried out at family level by the mother after delivery, through "kangaroo care", cuddling, breast-feeding, bathing, smiling, singing and carrying the baby on the back. All the above significantly contributes to the baby comprehending who is his/her mother, changes in temperature, discomfort after urination and stooling signifying hunger. At a later age, the father and other close family members are recognized because of proximity, voices and frequent care/attachment. As the child ages, relatives, neighbours and teachers also play their different roles and thus his/her comprehension increases.

The child also passes through several rites like, naming ceremony 7days after birth, circumcision (male/female) immediately after delivery or between 3-14years, marriage ceremony mostly from 13-18years for girls and 18-24years for boys (can be older/younger than the above age ranges) depending on the family/cast. First intercourse after marriage is usually celebrated as a test of virginity for girls (not done for boys) rather boys are tested for their manhood, whether they can penetrate/dis-virgin agirl or whether they can impregnate her. All these rites serve as a perfect fertility related school for the growing individual. He/she passes through so many teachings, narrations and demonstrations during this time to educate and increase his/her comprehension.

Application requires that acquired new knowledge is strengthened in the growing individual by making him/her to useit,apply the acquired knowledge, facts, techniques and rules in different ways and situations. This is done through verbs like apply, choose, demonstrate, dramatize, employ, illustrate, interpret, operate, practice, schedule, sketch, solve, use and write. These are done consistently/demonstrated to the individual throughout his/her life span by elderly siblings, parents, teachers, relatives and neighbours.

Analysis involves that as the child grows, his/her brain matures and therefore at a personal level, he/she can examine and break information into parts using his or her own discretion. He/she does this by using verbs such as analyze, appraise, calculate, categorize, compare, contrast, criticize, differentiate, discriminate, distinguish, examine, experiment, question and test. It is by performing the above that the individual is able to arrive at his/her decision. 
Synthesis requires that the individual's new knowledge/experience is assembled(into information)in a certain way by combining elements in a new pattern or proposing alternative solutions to the issue at hand. He/she uses verbs such asarrange, assemble, collect, compose, construct, create, design, develop, formulate, manage, organize, plan, prepare, propose, set up, write to be able to achieve the set goals/objectives.

Evaluation involves that theweight/extent of judgment is measured by assessing value, making judgments about information, validity of ideas or quality of work that have been produced.The individual does this byappraising, arguing, assessing, attaching, choosing, comparing, defending estimate, judging, predicting, rating, selecting, supporting, valuing, and evaluating decisions made and products achieved.

\section{Affective domain}

It is important to note that the target in the affective domain includes awareness and growth in attitudes, emotion, and feelings. It requires emotional reaction and ability to feel another living thing's pain or joy. It contains five levels identified by moving through the lowest order processes to the highest as follows:

Receiving is the lowest level to which the student passively pays attention. Without this level no learning can occur. In the case of the different age groups among the Mandingos, if anyone or group is being thought Islam, Arabic, Quran, Traditional or the customary laws, it requireslistening carefully and receiving the said lesson/s individually or as a group from parents, grand-parents, teachers, secret societies for men/women such as during circumcisions.

Responding requires that after receiving such lesson/s, not only does the person attend the learning process but he/she also responds and participates in some way to acknowledge understanding/not of the message.Moreover, in some instances, reciting the message repeatedly to either memorize or understand it better is encouraged.

Valuing requires that the respondent or student/learnersees worth in new information, he/she is further motivated to understand it better to receive that worth, reward or outcome.

Organizing involves that the person then devise ways and means of fitting the new information into existing schema and deciding how the new information makes sense for him/her. For example, feeding a child or an old person requires using the best food stuff for that age group, hand washing to prevent diseases such as pneumonia and diarrhea, buying the requisite medicaments to promote healing post circumcision and avoid sepsis, getting portable water for drinking and domestic use, properly disposing off stool and other highly infectious materials. Banning behaviours like open defecation through the provision of toilet facilities for every household and at public places.

Characterizing involves that as the worth of the information is recognized by the recipient, then he/she makes effort to incorporate the new information as part of the schema and exhibiting new behavior, attitude or belief in tandem with the said new information. This empowers the receiver immensely and consolidates that particular
information.If the information receiver has a positive attitude, his/her actions will lead to healthy life styles.

\section{Psychomotor domain}

This is a domain which is skill-based and therefore refers to the learning of skills. Physical skills involve the ability to move, act, or manually manipulate the body to perform a physical movement.It may be in the form of:

Imitation, involving the actualcopying of the action of another person such as how to wash hands, when to conduct circumcision, best types of food to use and at what age, how to breast-feed, when to introduce solid feeds to an infant, when to go to bed and amount of hours to sleep, when and how to pray, age at marriage, types of family planning to be used and whether to conduct abortion or not.

Manipulation, which is the physical carrying out/reproduction of activity from the instructions given such as how to do the actual female circumcision, time and type, which medication to buy and when and how to apply or drink it. What water temperature, soap, and steps/junctions in hand washing to apply. How to breast-feed a baby, talk to peers, siblings and the elderly to avoid quarrels and maintain law and order and how to dress including the type of clothes one wears bearing in mind the weather condition. Types of houses and number of people living in them to avoid congestion and allow cross ventilation. All these lead to healthy living conditions.

The psychomotor domain has been divided into three levels according to RH Dave (1967) which are:Develop precision requires that individual, after being imbued with the requisite knowledge and expertise, he/she will now have the confidence to execute the acquired skills reliably, independent of help from others. It also involves consolidation of those skills.

Articulation involves that the person will then have the capability of adapting and integrating his/her expertise to satisfy a non-standard objective to reach his/her own desired goal. This will be beneficial to him/her as an individual, his/her family and the society as a whole. Eventually, vices leading to ill health will be curtailed.

Naturalization is the health related knowledge, skills and expertise which will become part of the individual.He/she will develop anautomated and an unconscious mastery of activity and related skills at strategic level. This strengthens efficiency, improves productivity and limits the incidence and prevalence of diseases.

\section{SUMMARY OF FINDINGS}

From Table 1, we have seen that early marriages (12 to $15 y r s$ ) for girls and $18 y$ rs for boys, leads couples to have many children before their wives reach menopause. This is because of the long period of fecundity. When a woman or man gets married, the emphasis at marriage for the two families, is for the bride and the groom to have the ability to reproduce (have children soon after marriage). All Mandingos have the desire of having more of male childrenin marriage to enable them have someone who willeventually become the head of their family, own more shares ofinheritance and raise the status of the woman in the family. 
The joy is to have large families with thebelief that more children will help support their parents at old age and on the farms. Because the majority is Muslim, abortion is not accepted in the Mandingo community. The wish of every Mandingo couple is to have large families with plenty children, therefore, birth control through family planning, is discouraged. Only lactation separation is practiced sometimes. Because of the environmental and economic situations, there is high infant mortality rate which leads to more births to compensate for the loss. Similarly, children are needed to perform essential tasks (to economically support their siblings and parents). Living in rural areas leads to poor access and affordability of family planning services for those who desire to use them. Early age at first intercourse can lead to teenage and unwanted pregnancies mainly close relatives. Household headship (the man decides when to have sex and what number of children to have), so the woman has very little control if any about the number of children she should have. Ceremonies such as marriage, naming and circumcision can attract joy and funds which will influence fertility.

On the other hand, factors that inhibit fertility in Mandingo communities include the following: Avoidance of coitus for religious reasons such as during fasting, when breast feeding during the immediate postpartum period, and during menstruation. Mandingos' emphasis is for a man or woman to have continence and celibacy (abstaining from sexual relations before marriage and when widowed before remarrying). Because of their caste system, girls in higher castes don't normally marry to those in lower castes even if they will remain unmarried for long. Mandingos allow marriage to other tribes but women are not allowed to marry to others with different faith. Most of them in the urban areas, are exposed to mass media (therefore, sensitized) and do not practice most of the above cultures strictly. It's common for mothers to give the best part of the food to the household head (this leads to maternal and childhood malnutrition and anemia which contributes to death). Living in urban areas increases access and affordability of family planning services thereby can hinder fertility. Early menopause, especially where this genetic condition runs in a particular family, can limit the number of children. Obesity,women at around age 18 yrs with extra kilos which is common in Mandingos, leads to polycystic ovarian diseases and decreased fertility. Women who are too thin and deficient in leptin, the hormone that controls hunger and feelings of satiety, as seen among some Mandingos, leads to absence of menstrual periods. Mandingos have both extreme types of phenotypes among them.

It is worth noting that teachings in the Mandingo communities such as breast-feeding for at least 2years, hand washing with soap and clean water at key junctions; before eating, after using the toilet, after touching pets/animal fur, after blowing your nose/sneezing, before eating or feeding a child, before and after touching a wound, male circumcision and polygamy, will all contribute to maintaining healthy living. However, others like female circumcision/mutilation, preference to male sex, extended/large families, caste differences, tribe and religion differences, polygamy, to name but a few, can be resistant to health education efforts and therefore may impact negatively on the health of members of the tribe.The upbringing of the children of the Mandingo tribe is also characterized by the following implications of health education.

\section{CONCLUSION}

From the findings of this study, one can deduce that male dominance in decision making for family planning and sex, among the Mandingo tribe contributes significantly to the high fertility rate among this tribe. Women, even if they are not interested in having many children, do not necessarily have the power or the support to limit their fertility. Another powerful contributing factor is the love for male children for obvious reasons ranging from heading the family, having more shares of the inheritance, continuing the family linage, giving prestige to the mother, and helping in the farms. Polygamy and the desire for large families cannot also be under estimated in promoting fertility in the area.

The status quo can be shifted by empowering their females through educationand spending on them like they spend on their male kids. This will give them material and economic independence and also liberty for them to participate in decision making as equals.Pertaining to family planning, polygamy, sex and pregnancy, women should have the freedom to make choices and informed decisions regarding these issues. This will significantly contribute in stabilizing the fertility trend among the Mandingo tribe and also help to improve on their health and quality of life. The take home message is that, all Mandingos should endeavor to educate their children especially their girl child to the highest institutions of learning, if poverty, dependence, dominance and equity are to be achieved in the fertility cycle and important traditions that are handed down from generation to generation and contribute to good health, should also be nurtured and encouraged.

\section{REFERENCES}

[1] Architecture vernaculaireetpaysageculturelmandingue du Gberedou/Hamana -UNESCO World Heritage Centre Whc.unesco.org. Retrieved 2009-09-16.

[2] Baxter Magolda, M.B., \& King, P.M. (Eds.) (2004). Learning partnerships: Theories and models of practice to educate for self-authorship. Sterling, VA: Stylus Publishing.

[3] Bound To Africa - The Mandingo Legacy In The New World (PDF) Retrieved 2016-

[4] Broughton, J.M. (1975). The development of natural epistemology in years 11 to 16.(Unpublished Doctoral dissertation, Harvard University, 1975).

[5] Broughton, J.M. (1978). Development of concepts of self, mind, reality, and knowledge. In W. Damon (Ed.), Social cognition.New Directions for Child Development, No. 1. San Francisco: Jossey-Bass.

[6] Davison, M.L., King, P.M., \& Kitchener, K.S. (1990). Developing reflective thinking and writing. In R. Beach and S. Hynds (Eds.), Developing discourse practices in adolescence and adulthood. Norwood, NJ: Ablex.

[7] Dewey, J. (1933). How we think: A restatement of the relation of reflective thinking to the educative process. Lexington, MA: Heath.

[8] Dewey, J. (1938). Logic: The theory of inquiry. Troy, MO: Holt, Rinehart, \& Winston.

[9] EbouMomarTaal, Diplomatist, Economist, LinguistMandinka/Malinke/Dioula people of Mali, Cote d'Ivoire, Guinea,Burkina...EbouMomarTaalretrievwed 15/08/2016

[10] Ethnic groups - Guinea-Bissau. Nationsencyclopedia.com. Retrieved 2016-09-12. 
[11] Fischer, K.W. (1980). A theory of cognitive development: The control and construction of hierarchies of skills. Psychological Review, 87(6), 477-531.

[12] Flavell, J. (1963). The developmental psychology of Jean Piaget. New York: Van Nostrand Reinhold.

[13] Flavell, J. (1971). Stage related properties of cognitive development. Cognitive Psychology, 2(4), 421-453.

[14] Flavell, J. (1977). Cognitive development. Englewood Cliffs, NJ: Prentice-Hall.

[15] Hofer, B.K., \&Pintrich, P.R. (1997). The development of epistemological theories: Beliefs about knowledge and knowing and their relation to learning. Review of Educational Research, 67(1), 88-140.

[16] Hofer, B.K., \&Pintrich, P.R. (Eds.). (2002). Personal epistemology: The psychology of beliefs about knowledge and knowing. Mahwah, NJ: Lawrence Erlbaum Associates, Inc.

[17] Ivory Coast - Ethnic Groups And Languages. Countrystudies.us. (Retrieved 2016-10-16).

[18] Joshua Project (2009). "Mandingo, Mandinka of Senegal Ethnic People Profile".

[19] Joshuaproject.net. (Retrieved 2016-09-12).

[20] Kegan, R. (1982). The evolving self. Cambridge, MA: Harvard University Press.

[21] King, P.M. (1990). Assessing development from a cognitive developmental perspective.In D. Creamer and Associates (Eds.), College student development: Theory and practice for the 1990's. Alexandria, VA: ACPA Media.

[22] King, P.M. (Ed.) (1992). Special issue on Reflective Judgment, Journal of Liberal Education, 78, Whole number 1.

[23] Krathwohl, D. R., Bloom, B. S., Masia, B. B.; (1964), "Taxononmy of Educational Objectives. Handbook II: The affective domain.

[24] Logon, Roberta A. (2007)."Sundiata of mali". Calliope 17 (9): 34-38.

[25] Lorin W. Anderson, David R. Krathwohl, Peter W. Airasian, Kathleen A. Cruikshank, Richard E. Mayer, Paul R. Pintrich, James Raths and Merlin C. Wittrock (Eds.) Addison Wesley Longman, (2001), A Taxonomy for Learning, Teaching, and Assessing — A Revision of Bloom's Taxonomy of Educational Objectives.

[26] Mandinka in Mali. National Geographic Magazine's index has no record of such an article. http://publicationsindex.nationalgeographic.com/.

[27] Mandinka Tribe, Gambia. Accessgambia.com. (Retrieved 2016-09-10).

[28] Mentioned in a number of interviews, including Mr. T: Pity The Fool, allhiphop.com, Published, (2006). Mr. T gives a 1977 date, for an article with photos.

[29] Quinn, Charlotte A.; Quinn, Charlotte A. (1973). "Mandingo Kingdoms of the Senegambia:

[30] Romiszowski, A (1999), The Development of Physical Skills: Instruction in the Psychomotor Domain, Chapter 19, Instructional Design Theories and Models: A New Paradigm of Instructional Theory, Volume II.

[31] Schaffer, Matt (2003). Djinns, Stars, and Warriors: Mandinka Legends from Pakao,

[32] Senegal. Leiden: Springer-Brill. p. 6.

[33] Taxonomy of Educational Objectives (1956): The Classification of Educational Goals; pp. 201-207;B. S. Bloom (Ed.) Susan Fauer Company, Inc.

[34] Traditionalism, Islam and European Expansion". The American Historical Review 78 (5): 1506-1507.doi:10.2307/1854194. $\underline{\text { JSTOR }} \underline{1854194}$ 